\title{
Right heart pressure determination by Doppler in infants with tricuspid regurgitation
}

Jonathan R Skinner, A Graham Stuart, John O'Sullivan, Alison Heads, Richard J Boys, Stewart Hunter

\begin{abstract}
Doppler and direct measurements of right ventricle to right atrial pressure drop were made during cardiac catheterisation on 28 occasions in 26 infants with congenital heart disease. Age was 10 days to 12 months (median 4.5 months), and weight was 3.1 to $9.0 \mathrm{~kg}$ (median $4.7 \mathrm{~kg}$ ). We measured peak velocity of tricuspid regurgitation by continuous wave Doppler, and the pressure drop was calculated using the modified Bernoulli equation $\left(\Delta p=4 v^{2}\right)$.
\end{abstract}

There was a high correlation $(r=0.95)$ between direct and Doppler measurements. Doppler values tended to underestimate the right ventricle to right atrial pressure drop, but this was not of clinical significance (mean $2 \mathrm{~mm} \mathrm{Hg}$ ). The 95\% confidence interval for the Doppler velocity was -0.41 to $+0.26 \mathrm{~m} / \mathrm{sec}$, and was consistent across the range of pressures studied.

Variability between observers was tested, by two observers performing sequential paired examinations on 16 newborn babies with tricuspid regurgitation. The coefficient of repeatability was $6.3 \mathrm{~mm} \mathrm{Hg} \mathrm{(95 \%} \mathrm{confidence} \mathrm{interval}$ 4.7 to $9.5 \mathrm{~mm} \mathrm{Hg})$ or $0.26 \mathrm{~m} / \mathrm{sec}(0.18$ to $0.50 \mathrm{~m} / \mathrm{sec}$ ).

This method of right ventricular pressure estimation, validated previously only in older children and adults, is a reproducible and accurate technique in infants with tricuspid regurgitation. (Arch Dis Child 1993; 69: 216-220)

None of the available non-invasive methods for estimating pulmonary arterial pressure have been validated in the newborn, despite the obvious clinical advantages. In adults and children, accurate non-invasive determination of pulmonary arterial pressure can be made by measuring the peak velocity of tricuspid regurgitation and application of the modified Bernoulli equation ${ }^{1-10} \quad\left(\Delta \mathrm{p}=4 \mathrm{v}^{2}\right.$, where $\Delta \mathrm{p}=$ pressure drop $(\mathrm{mm} \mathrm{Hg})$, and $\mathrm{v}=$ velocity in $\mathrm{m} / \mathrm{sec}$ ). The systolic pressure drop from right ventricle to right atrium is calculated, and an allowance for right atrial pressure added to estimate systolic pulmonary arterial pressure.

While there have been many studies in adults and children comparing direct measurement by cardiac catheterisation with Doppler derived values (see the table), surprisingly none have concentrated on infants, though there are theoretical reasons why the technique might be less accurate in the smaller subject. In vitro experiments by Holen et al demonstrated that underestimation of the true pressure gradient occurred when applying the modified Bernoulli equation to a valve orifice below $3.5 \mathrm{~mm}$ in diameter or flow velocities below $3 \mathrm{~m} / \mathrm{sec} .{ }^{11}$ The tricuspid valve is obviously much smaller in babies, and although the area of regurgitation cannot be measured accurately, it is logical to assume that this is also much smaller; and probably less than $3.5 \mathrm{~mm}$ in diameter in the newborn, particularly when the regurgitation is trivial. The combination of low velocity (less than $3 \mathrm{~m} / \mathrm{sec}$ ), which is common in the newborn, ${ }^{12} 13$ with small regurgitant area could theoretically lead to significant underestimation of the true pulmonary arterial pressure.

The original aims of this study were to investigate the validity and repeatability of the method in the newborn. However, as neonatal cardiac catheterisation is now rare in paediatric cardiology, the study group was expanded to include babies up to 1 year of age. The aims of this study were therefore: (1) to compare direct and Doppler determined right ventricular to right atrial (RV-RA) pressure drop in infants
Department of
Paediatric Cardiology, Freeman Hospital, Newcastle upon Tyne J R Skinner A G Stuart

J O'Sullivan

A Heads

S Hunter

\section{Department of}

Mathematics and

Statistics, University

of Newcastle upon

Tyne

R J Boys

Correspondence to: Dr J R Skinner, Departmen of Paediatric Cardiology, Birmingham Children's Hospital, Ladywood, Birmingham B16 8ET

Accepted 14 April 1993
Previous studies evaluating Doppler determination of pulmonary arterial pressure by measurement of the peak velocity of tricuspid regurgitation and application of the modified Bernoulli equation

\begin{tabular}{|c|c|c|c|c|c|c|c|}
\hline First author & Year & $\begin{array}{l}\text { No } \\
\text { studied }\end{array}$ & $\begin{array}{l}\text { No } \\
<2 \text { years old }\end{array}$ & Patient group ${ }^{\star}$ & Time of Doppler study† & Correlation & $\begin{array}{l}\text { Standard error } \\
(\mathrm{mm} \mathrm{Hg})\end{array}$ \\
\hline Yock $^{1}$ & 1984 & 62 & 0 & Cardiology & $\begin{array}{l}\text { Within } 24 \text { hours, } \\
14 \text { simultaneous }\end{array}$ & 0.93 & $8 \cdot 0$ \\
\hline $\begin{array}{l}\text { Berger }^{2} \\
\text { Currie }^{3} \\
\text { Skjaerpe }^{4} \\
\text { Vasquez de Prada }^{5} \\
\text { Chan }^{6} \\
\text { Laaban }^{7} \\
\text { Gallet }^{8} \\
\text { Stevenson }^{9} \\
\text { Tramarin }^{10}\end{array}$ & $\begin{array}{l}1985 \\
1985 \\
1986 \\
1987 \\
1987 \\
1989 \\
1989 \\
1989 \\
1991\end{array}$ & $\begin{array}{r}69 \\
111 \\
70 \\
34 \\
36 \\
27 \\
17 \\
50 \\
30\end{array}$ & $\begin{array}{l}0 \\
16 \\
0 \\
0 \\
6 \\
0 \\
0 \\
?-\text { mean } 6.9 \text { y } \\
0\end{array}$ & $\begin{array}{l}\text { Mixed } \\
50 \text { CHD } \\
\text { Cardiology } \\
\text { Cardiology } \\
\text { Cardiology } \\
\text { COPD } \\
\text { COPD } \\
\text { CHD } \\
\text { COPD }\end{array}$ & $\begin{array}{l}\text { Simultaneous } \\
\text { Simultaneous } \\
\text { Within } 2 \text { days } \\
\text { Within } 2 \text { days } \\
\text { Simultaneous } \\
\text { Within } 2 \text { days } \\
\text { Average } 2 \cdot 5 \text { days apart } \\
\text { Mostly simultaneous } \\
\text { Within } 3 \text { days }\end{array}$ & $\begin{array}{l}0.97 \\
0 \cdot 96 \\
0 \cdot 97 \\
0 \cdot 96 \\
0 \cdot 89 \\
0 \cdot 65 \\
0 \cdot 93 \\
0 \cdot 96 \\
0 \cdot 73\end{array}$ & $\begin{array}{l}4 \cdot 9 \\
7 \cdot 0 \\
6 \cdot 1 \\
\text { Not stated } \\
7 \cdot 4 \\
9 \cdot 0 \\
\text { Not stated } \\
6 \cdot 9 \\
7 \cdot 4\end{array}$ \\
\hline
\end{tabular}

*Cardiology: adult cardiology, CHD: congenital heart disease, COPD: chronic obstructive pulmonary disease.

†'Time of Doppler study' is time between the Doppler and catheterisation studies. 
under 1 year of age undergoing cardiac catheterisation and (2) to determine limits of interobserver variability of the method in newborn babies.

\section{Patients}

There were two study groups.

\section{GROUP 1 (DOPPLER VERSUS DIRECT MEASUREMENT)}

Group 1 comprised 28 infants (less than 1 year of age) with congenital heart disease found to have Doppler evidence of tricuspid regurgitation. Thirty paired measurements were made on the 28 babies. Three babies were included who were in intensive care with indwelling pulmonary arterial and right atrial pressure lines. Two of these babies had paired measurements on consecutive days. The other babies underwent formal cardiac catheterisation. Two values were excluded because of haemodynamic instability between Doppler and catheter measurements. There were therefore 28 completed studies from 26 babies. Weight range was 3.1 to $9.0 \mathrm{~kg}$ (median $4.7 \mathrm{~kg}$ ) and age range was 10 days to 12 months (median 4.5 months). Eighteen babies weighed less than $5 \mathrm{~kg}$ and 20 were under 6 months of age. The study population included three postoperative patients (two babies who had anomalous pulmonary venous drainage and one with a ventricular septal defect), 11 babies with a ventricular septal defect, four with a complete atrioventricular septal defect (one also had Fallot's tetralogy), three with isolated pulmonary stenosis, one with cardiomyopathy, one with arterial trunk, one with partial atrioventricular septal defect, one with pulmonary atresia with ventricular septal defect, and one baby with a hypoplastic left heart.

GROUP 2 (VARIABILITY BETWEEN OBSERVERS) Group 2 comprised 16 newborns. Ten babies had structurally normal hearts and were examined in the first 72 hours of life. Nine of these were premature babies (28-36 weeks' gestation) and one was at full term. Four of the premature babies had mild hyaline membrane disease (but were haemodynamically stable). Six babies had congenital heart disease and were born at term.

\footnotetext{
Methods

GROUP 1 (DOPPLER VERSUS DIRECT MEASUREMENT)

All infants were under general anaesthesia when the Doppler and catheterisation measurements were taken. Doppler measurements were made before venepuncture. Catheter measurements were made with a single catheter, before angiography, recording peak right ventricular pressure, and then withdrawing to record mean right atrial pressure. This method was used in preference to two catheters recording simultaneous pressures to avoid enlargement of the area of tricuspid
}

regurgitation caused by leaving a catheter through the tricuspid valve. Oscillometric systemic blood pressure was recorded with the Doppler and catheter measurements. As some haemodynamic variability is expected at all times, when the systolic pressure changed by more than $10 \mathrm{~mm} \mathrm{Hg}$ between the two measurements, the values were excluded from the study.

Doppler measurements were made by a single observer (JRS) with a Sonos 1000 ultrasound machine, using a stand alone $2 \cdot 2 \mathrm{MHz}$ continuous wave Doppler probe in the manner described previously. ${ }^{12}$ The spectral display was adjusted to achieve a clear velocity profile, and the low velocity (noise) filter was set on maximum. The maximal velocity was taken as being in line with flow. In four babies with complete atrioventricular septal defect, colour flow guided continuous wave Doppler was used. Catheterisation pressures were made using a strain gauge with either a BentleyTrantec or a Truck transducer. Signals were transmitted via isolation amplifiers at the foot of the bed to pressure amplifiers in the main console. Measurements for this study were made from a Siemens Elema Mingograph strip chart recording, by a single independent observer who was unaware of the Doppler results (AGS). Mean right atrial pressure was subtracted from peak right ventricular pressure to determine the maximal RV-RA pressure drop.

The catheter derived measurements were reanalysed by a third observer (JO'S) to determine observer error associated with the catheter measurement.

\section{GROUP 2 (VARIABILITY BETWEEN OBSERVERS)}

Two experienced observers (JRS, AH) measured the peak velocity of tricuspid regurgitation in 16 newborn babies. Examinations were performed within 2-3 minutes of each other, and the babies were resting quietly.

\section{STATISTICAL ANALYSIS}

Measurements were compared using Spearman correlations and the method introduced by Bland and Altman. ${ }^{14}$

\section{Results}

\section{(1) VALIDATION AGAINST DIRECT}

\section{MEASUREMENT}

The results are presented in figs 1 to 4 . In fig 1 , the two values of the peak right ventricle to right atrial (RV-RA) pressure drop are plotted against each other in the same manner as previous validatory studies $(r=0 \cdot 95)$. Standard error for the estimate was $5 \cdot 1 \mathrm{~mm} \mathrm{Hg}$. There is considerable spread around the correlation line. Three 'Bland-Altman' plots (figs 2-4) give more insight into the level of agreement between the methods. Doppler derived values are compared with peak right ventricular pressure in fig 2: there is a mean underestimation of $5.8 \mathrm{~mm} \mathrm{Hg}, 95 \%$ confidence interval for a single difference was $-17 \cdot 4$ to $+7 \cdot 0 \mathrm{~mm} \mathrm{Hg}$. 


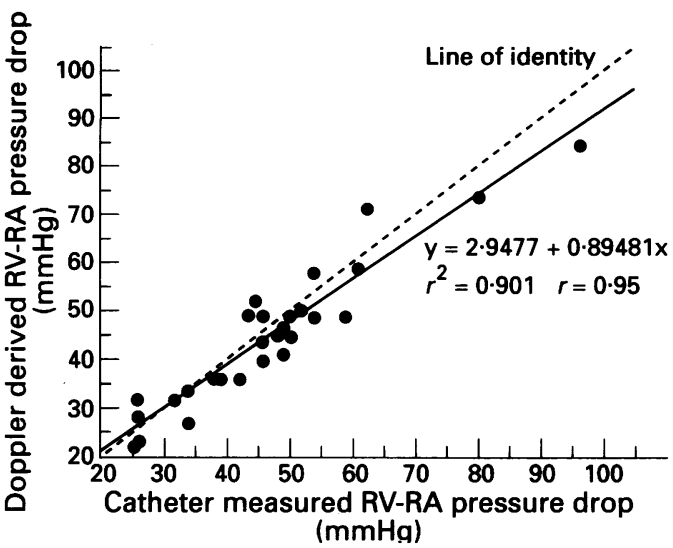

Figure 1 Correlation of Doppler and catheter derived $R V-R A$ pressure drop.

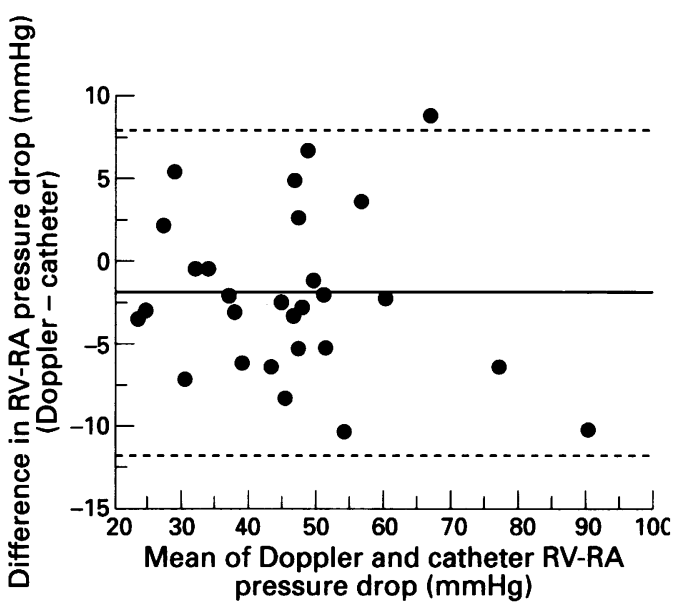

Figure 3 The difference between Doppler and catheter derived $R V-R A$ pressure drop, with results expressed in $\mathrm{mm} \mathrm{Hg}$.

Comparison of the Doppler and catheter measured RV-RA pressure difference (fig 3) shows closer agreement, but the Doppler values still tend to underestimate the true pressure drop (mean $=-2.0 \mathrm{~mm} \mathrm{Hg}, 95 \%$ confidence interval for a single difference -11.8 to $+7 \cdot 8 \mathrm{~mm} \mathrm{Hg}$ ).

To determine the confidence interval for the velocity measured by Doppler, the RV-RA pressure drop measured by catheter was calculated in $\mathrm{m} / \mathrm{sec}$ by using the Bernoulli equation in reverse $\left(p=4 v^{2}\right.$, therefore $\mathrm{v}=\mathrm{V} \mathrm{p} / 4)$. For example, an RV-RA pressure drop of $36 \mathrm{~mm} \mathrm{Hg}=3 \mathrm{~m} / \mathrm{sec}$. The derived values have been plotted against the Doppler measurements in fig 4 . The resulting $95 \%$ confidence interval for the tricuspid regurgitation jet velocity is -0.41 to $+0.26 \mathrm{~m} / \mathrm{sec}$.

Catheter measurements were reanalysed by a third observer. All but one measurement agreed to within $\pm 4 \mathrm{~mm} \mathrm{Hg}$, one differed by $6 \mathrm{~mm} \mathrm{Hg}$. Therefore some of the disagreement between the two methods can be explained by subjectivity in interpretation of the catheterisation results.

(2) VARIABILITY BETWEEN OBSERVERS

Values in the 16 newborn babies ranged from $19 \mathrm{~mm} \mathrm{Hg}$ to $100 \mathrm{~mm} \mathrm{Hg}$, though all but two were below $60 \mathrm{~mm} \mathrm{Hg}$. The coefficient of repeatability ${ }^{14}$ was $6.3 \mathrm{~mm} \mathrm{Hg}$. The coefficient

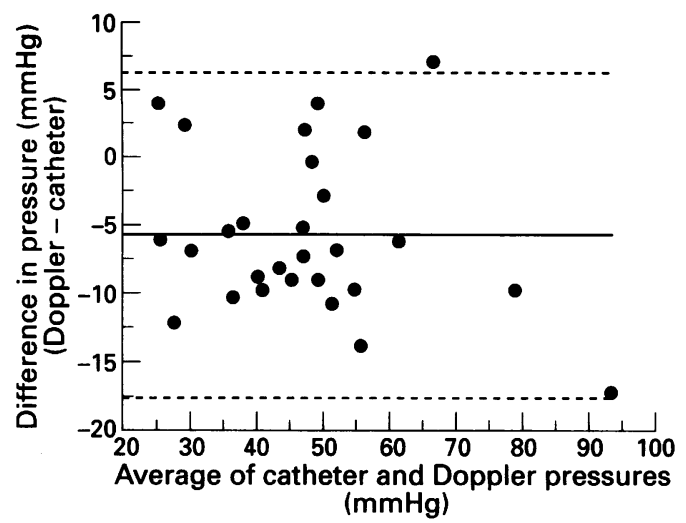

Figure 2 The difference between Doppler derived $R V-R A$ pressure drop and peak right ventricular pressure measured by catheter.

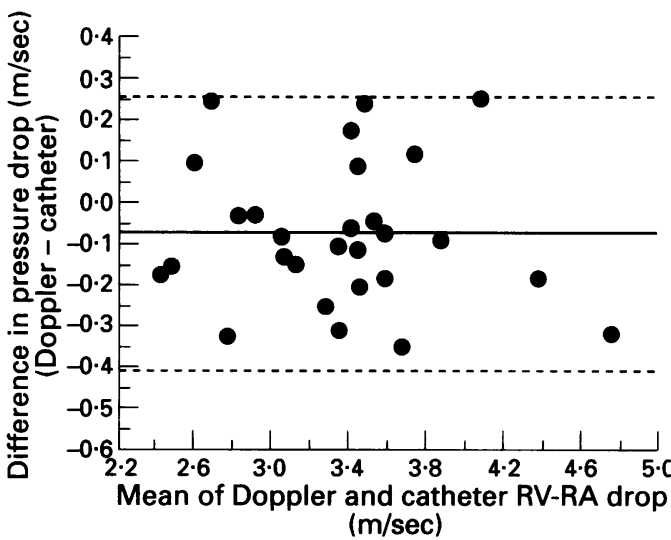

Figure 4 The difference between Doppler and catheter derived $R V-R A$ pressure drop, with results expressed as $\mathrm{m} / \mathrm{sec}$ (see text).

of repeatability is calculated in a similar way to the method shown in figs 2 to 4 , comparing paired measurements between different observers rather than between different techniques, and represents $95 \%$ confidence intervals of repeatability. The $95 \%$ confidence interval for this coefficient, calculated because of small sample size, was 4.7 to $9.5 \mathrm{~mm} \mathrm{Hg}$. In terms of the measured tricuspid regurgitant velocity, the coefficient of repeatability was $0.26 \mathrm{~m} / \mathrm{sec}$, with a $95 \%$ confidence interval of 0.18 to $0.50 \mathrm{~m} / \mathrm{sec}$.

\section{Discussion}

This study shows close agreement between direct and indirect measurement of RV-RA pressure drop, although the tricuspid regurgitation technique marginally underestimated the true pressure drop on average by $2 \mathrm{~mm} \mathrm{Hg}$. This underestimation may be due to energy loss due to viscous friction through the small valve orifice, or due to failure to align the Doppler beam accurately with the direction of the regurgitant jet.

In the three babies with a pressure gradient of more than $60 \mathrm{~mm} \mathrm{Hg}$, Doppler measurements, expressed in $\mathrm{mm} \mathrm{Hg}$, were less accurate than at lower pressures (fig 3). However, when the values were expressed in $\mathrm{m} / \mathrm{sec}$ (fig 4 ), the margin of error at high pressures is no different from that seen at lower pressures. Comparison 
of fig 3 and 4 therefore suggests that it is better to express the confidence interval of the Doppler measurement in terms of velocity $(-0.41$ to $+0.26 \mathrm{~m} / \mathrm{sec})$ rather than pressure because the same measurement error at higher velocities results in a larger error in calculated pressures. This is logical as measurement errors at the higher velocities are also squared and multiplied by four. When this confidence interval is applied, the method is seen to be more accurate, in terms of the derived pressure drop in $\mathrm{mm} \mathrm{Hg}$, at lower velocities. The measured tricuspid regurgitation jet is on average an underestimate, so the confidence interval to determine the 'true' pressure is -0.26 to $+0.41 \mathrm{~m} / \mathrm{sec}$. For example, a tricuspid regurgitant velocity of $2 \mathrm{~m} / \mathrm{sec}$ indicates a true RV-RA pressure drop of 13 to $23 \mathrm{~mm} \mathrm{Hg}$ (range $=10 \mathrm{~mm} \mathrm{Hg}$ ), and a velocity of $4 \mathrm{~m} / \mathrm{sec}$ indicates 56 to $78 \mathrm{~mm} \mathrm{Hg}$ (range $=22 \mathrm{~mm}$ $\mathrm{Hg}$ ). The confidence interval, in terms of $\mathrm{mm}$ $\mathrm{Hg}$, has doubled with a doubling of the velocity. Furthermore, a given change in pressure drop at lower values will produce a bigger change in regurgitant velocity than at higher values. For example, when there is a change of $10 \mathrm{~mm} \mathrm{Hg}$ in the RV-RA pressure from 20 to $30 \mathrm{~mm} \mathrm{Hg}$, velocity changes from $2 \cdot 2$ to $2.7 \mathrm{~m} / \mathrm{sec}$ (a rise of $0.5 \mathrm{~m} / \mathrm{sec}$ ), whereas if the pressure rises by the same amount, from 60 to $70 \mathrm{~mm} \mathrm{Hg}$, velocity changes from 3.9 to 4.2 (a rise of $0.3 \mathrm{~m} / \mathrm{sec}$ ). The first $10 \mathrm{~mm} \mathrm{Hg}$ change can be detected 'with confidence' by the tricuspid regurgitation technique, whereas the second cannot.

Previous validatory studies of the tricuspid regurgitation technique have compared results of direct and indirect measurement using linear regression analysis. Bland and Altman criticised this technique in testing the agreement of two measurements of the same factor because correlation $(r)$ tests the relationship of two variables, not the agreement between them. ${ }^{14}$ The alternative method allows the production of confidence intervals, which are of more clinical value than a correlation coefficient. Visual interpretation of the plots in this paper demonstrates that there was no obvious variation in agreement across the range of pressures in this study, particularly when the results were expressed in $\mathrm{m} / \mathrm{sec}$. This is in contrast to the large variation in agreement over the pressure range in determining pressure drop across ventricular septal defects by Doppler and catheter. ${ }^{15}$

Despite the limitations of the correlation coefficient in this setting, it is clear from the table that the tricuspid regurgitation technique produces a consistently close correlation with direct measurement. The exceptions are two studies involving adults with chronic obstructive pulmonary disease. The study of Laaban et $a l^{7}$ and Tramarin et al ${ }^{10}$ both had lower correlation coefficients, of 0.65 and 0.73 respectively. However, these patients are technically difficult to scan because of hyperinflated lungs and the consequent poor 'echo window'. Furthermore, the Doppler studies were done hours or days apart from cardiac catheterisation, and a significant temporal variability is to be expected in this group. Taken overall, the results are better than any of the techniques using timing of systolic events at the pulmonary artery to determine pulmonary arterial pressure. ${ }^{16-18}$ Two studies comparing systolic time intervals with the tricuspid regurgitation method against direct measurement both concluded that the tricuspid regurgitation method was superior, provided that regurgitation was actually present. ${ }^{69}$

There were, unfortunately, only three neonates in the first part of this study because neonatal catheterisation is now rarely necessary. However, 18 babies weighed less than $5 \mathrm{~kg}$, so that small subject size does not appear to influence the validity of this method adversely, and between-observer error, studied in newborns, was acceptable. Furthermore, lower RV-RA pressure drops, below $40 \mathrm{~mm}$ $\mathrm{Hg}$, are more frequent in this study than in previous studies and they were determined accurately by the tricuspid regurgitation technique. It is therefore fair to assume that the technique is valid in the term newborn baby. Although this study alone cannot be taken as validation for the use of the tricuspid regurgitation technique in the low birth weight or preterm newborn, our previous report using this technique in healthy term and preterm newborns over the first three days of life produced apparently appropriate pulmonary arterial pressure values when expressed as a ratio of systemic arterial pressure. 12

Small valve orifice and low blood velocity, the theoretical sources of error of this technique in newborns, did not lead to serious underestimation of pressure drop. Perhaps the reason is that the physical properties of a healthy, but slightly regurgitant valve, are very different from the stiff, firm edged orifice created in the in vitro experiments of Holen et al, and the shape of an orifice, and its surface morphology are important in the generation of friction.

In summary, the measurement of peak tricuspid regurgitation and application of the modified Bernoulli equation predict the right ventricle to right atrial pressure drop in infants and newborns with reasonable accuracy, and provides a more reliable estimate of pulmonary arterial pressure than systolic time intervals, or velocity across a ventricular septal defect. However, it is limited by the fact that it is only feasible in babies with tricuspid regurgitation, which is not present in all babies, including those with high pulmonary arterial pressure. We have reported previously that many healthy term babies with high pulmonary arterial pressure shortly after birth do not have tricuspid regurgitation sufficient to generate a measurable signal, ${ }^{12}$ even though premature babies with hyaline membrane disease usually do. ${ }^{13}$ The feasibility of the technique can be increased in some subjects by using intravenous saline contrast to enhance a weak regurgitant signal. ${ }^{19}$

An allowance for right atrial pressure in determining peak pulmonary arterial pressure may need to include a small allowance, of about $2 \mathrm{~mm} \mathrm{Hg}$, for the tendency of the 
method to slightly underestimate the true pressure drop, added to the estimated right atrial pressure. When right atrial pressure is not known, the estimated value should vary according to the clinical condition, ${ }^{20}$ but an average total allowance of about $6 \mathrm{~mm} \mathrm{Hg}$ would be appropriate from the present study. However, this study suggests that it is better, particularly when individual values are of clinical importance, to express tricuspid regurgitation jet values in terms of velocity $(\mathrm{m} / \mathrm{sec})$ rather than as a pressure drop ( $\mathrm{mm} \mathrm{Hg}$ ).

Dr Skinner was supported by the National Heart Research Fund. We thank Dr H Bain and Dr C Wren for allowing us to study their patients.

1 Yock PG, Popp RL. Noninvasive estimation of right ventricular systolic pressure by Doppler ultrasound in patients with tricuspid regurgitation. Circulation 1984; 70; 657-62.

2 Berger M, Haimowitz A, Van Tosh A, Berdoff RL, Goldberg E. Quantitative assessment of pulmonary hypertension in patients with tricuspid regurgitation using continuous wave Doppler ultrasound. $\mathcal{f} \mathrm{Am}$ Coll Cardiol 1985; 6: 359-65.

3 Currie PJ, Seward JB, Chan $\mathrm{K}$, et al. Continuous wave Doppler determination of right ventricular pressure: a
simultaneous Doppler-catheterisation study in 127 patients. F Am Coll Cardiol 1985; 6: 750-6.

4 Skjaerpe $T$, Hatle $L$. Noninvasive estimation of systolic pressure in the right ventricle in patients with tricuspid regurgitation. Eur Heart $\mathcal{f} 1986$; 7: 704-10.

5 Vazquez de Prada JA. Ruano J, Martin-Duran R, et al. Noninvasive determination of pulmonary arterial systolic pressure by continuous wave Doppler. Int $\mathcal{f}$ Cardiol 1987 ; pressure by con $177-84$.

6 Chan K-L, Currie PJ, Seward JB, Hagler DJ, Mair DD, Tajik AJ. Comparison of three Doppler ultrasound methods in the prediction of pulmonary arterial pressure. f Am Coll Cardiol 1987; 9: 549-54.

7 Laaban JP, Diebold B, Zelinski R, Lafay M, Raffoul H, Rochemaure J. Noninvasive estimation of systolic pul- monary artery pressure using Doppler echocardiography in patients with chronic obstructive pulmonary disease. Chest 1989; 96: 1258-62.

8 Gallet B, Saudemont JP, Bourdon D, et al. Dopplerechocardiographic evaluation of pulmonary arterial hypertension in patients with chronic obstructive lung disease. Arch Mal Coeur 1989; 82: 1575-83.

9 Stevenson JG. Comparison of several noninvasive methods for estimation of pulmonary artery pressure. $7 \mathrm{Am} \mathrm{Soc}$ for estimation of pulmonary
Echocardiogr 1989; 2: 157-71.

10 Tramarin R, Torbicki A, Marchandise B, Laaban JP, Morpurgo M. Doppler echocardiographic evaluation of pulmonary artery pressure in chronic obstructive pulmonary disease. A European multicentre study. Eur Heart f 1991; 12: 103-11.

11 Holen J, Aaslid R, Landmark K, Simonson S, Ostrem T. Determination of effective orifice area in mitral stenosis from non-invasive ultrasound Doppler data and mitral flow rate. Acta Medica Scandinavica 1977; 201: 83-8.

12 Skinner JR, Boys RJ, Hunter S, Hey EN. Noninvasive determination of pulmonary arterial pressure in the determination of pulmonary arterial pressure in

13 Skinner JR, Boys RJ, Hunter S, Hey EN. Pulmonary and systemic arterial pressure in hyaline membrane disease. Arch Dis Child 1992; 67: 366-73.

14 Bland JM, Altman DG. Statistical methods for assessing agreement between two methods of clinical measurement. Lancet. 1986; i: 307-10.

15 Houston AB, Lim MK, Doig WB, Reid JM, Coleman EN. Doppler assessment of the interventricular pressure drop in patients with ventricular septal defects. $\mathrm{Br}$ Heart $\mathcal{f}$ in patients with

16 Hirschfeld S, Meyer R, Schwarz DC, Korhagen J, Kaplan S. The echocardiographic assessment of pulmonary artery pressure and pulmonary vascular resistance. Circulation 1975; 52: 642-9.

17 Kosturakis D, Goldberg SJ, Allen HD, Loeber C. Doppler echocardiographic prediction of pulmonary arterial pressure in congenital heart disease. Am F Cardiol 1984 53: $1110-5$.

18 Serwer GA, Cougle AG, Eckerd JM, Armstrong BE. Factors affecting use of the Doppler-determined time from flow onset to maximal pulmonary artery velocity for measurement of pulmonary artery pressure in children measurement of pulmonary art

19 Beard II JT, Byrd III BF. Saline contrast enhancement of trivial Doppler tricuspid regurgitation signals for estimating pulmonary artery pressure. $\mathrm{Am} \mathcal{F}$ Cardiol 1988; 62: 486-8.

20 Skinner JR, Milligan DWA, Hunter S, Hey EN. Central venous pressure in the ventilated neonate. Arch Dis Child 1992; 67: 374-7. 